\title{
LOAD-BEARING CAPACITY OF COMPRESSED CONCRETE ELEMENTS SUBJECTED TO REPEATED LOAD STRENGTHENED WITH CFRP MATERIALS
}

\author{
Wojciech Trapko ${ }^{1}$, Tomasz Trapko ${ }^{2}$ \\ Institute of Building Engineering, Wroclaw University of Technology, \\ Pl. Grunwaldzki 11, 50-370 Wroclaw, Poland \\ E-mail: ${ }^{2}$ tomasz.trapko@pwr.wroc.pl (corresponding author) \\ Received 16 Jan. 2012; accepted 27 Mar. 2012
}

\begin{abstract}
This paper presents the results of experimental investigations of compressed concrete elements behaviour subjected to monotonic and cyclic load strengthened with CFRP materials. Two types of CFRP strengthening were applied during the experiment - longitudinal strips and/or transverse sheets. The results obtained allowed to draw conclusions concerning the possibility of representing a stress-strain monotonic curve with a curve of cyclic strains. The influence of load history on strain parameters of the investigated elements was found. The influence of the strengthening pattern and the state of effort on Young modulus and residual strains was analyzed. Moreover, observations were made of the disadvantageous effect of cyclic loads on strengthening durability, which lead to deformation or partial delamination of external CFRP reinforcement.
\end{abstract}

Keywords: CFRP, confinement, concrete, cyclic loading.

\section{Introduction}

Wide popularization of FRP systems and dynamic development of knowledge in the area of possible applications for this technology allowed to apply them for strengthening elements subjected to cyclic loads. Those characteristic loads occur in cases of supporting structures of cranes and trestle bridges, supports of bridge spans and structures built in areas of seismic activity (Lagoda 2005). The latest findings show that application of FRP confinement in columns causes an increase of their load-bearing capacity. It stems from limitation of strains in the concrete core. This increase depends on many parameters such as: compressive concrete strength, intensity and type of longitudinal and transverse strengthening, steel reinforcement ratio, cross-section shape and column slenderness (Campione, Miraglia 2003; Demers, Neale 1994; Ignatowski, Kamińska 2004; Rochette, Labossière 2000; Trapko et al. 2012; Trapko, Musiał 2010, 2011). Extensive studies conducted upon plain and reinforced concrete specimens under monotonic loads are generally known. They underlie the $\sigma-\varepsilon$ models of FRP strengthened concrete.

Many studies have examined the stress-strain behaviour of unconfined and steel-confined concrete under cyclic compression (Gorzelańczyk 2011; Hoła 2000, 2002; Sakai, Kawashima 2006; Sinha et al. 1964). However, there are no accurate results of investigations and analyses of cyclic load influence on compressed elements strengthened with FRP composites. Nowadays, pioneer publications concerning these issues have started to emerge (Ozbakkaloglu et al. 2008; Shao et al. 2006;
Varma et al. 2009), but there is still no exhaustive information on interaction of concrete core and external strengthening. Concurrently with the experimental studies, the $\sigma-\varepsilon$ model of FRP strengthened concrete subjected to cyclic load is being developed (Shao et al. 2006).

Varma et al. (2009) carried out a comparative analysis of cyclic and monotonic compression of reinforced concrete elements fully or partially confined with a CFRP sheet. 54 specimens were tested, each with diameter of $200 \mathrm{~mm}$ and height of $600 \mathrm{~mm}$. The authors analyzed the influence of strength of concrete, stiffness of strengthening, arrangement of bands (rings) across the CFRP sheet and the type of loads as well. The following changeable parameters were assumed in the investigative program: breadth of bands -45 or $60 \mathrm{~mm}$, amount of bands along the element height $-4,6$ or full confinement, amount of sheet layers in a single band -3 or 5 and the diameter of steel rebars in the cross-section $-4 \phi 8$ or $4 \phi 10$. The authors observed a high consistency of the cyclic $\sigma-\varepsilon$ curve and the curve for monotonic load. The $\sigma-\varepsilon$ curve in the first phase has a linear course and depends mainly on properties of concrete. Subsequently, it runs nonlinearly and afterwards it regains linear character. In the last phase, the course of the $\sigma-\varepsilon$ curve depends on properties and intensity of the CFRP strengthening. Tendency of stiffness to decrease due to successive load-unload cycles with strains in specimens increasing was observed.

Ozbakkaloglu et al. (2008) raised the issue of cyclic loads on cylindrical specimens out of HSC - highstrength concrete and NSC - normal-strength concrete, strengthened with FRP composites. 18 cylindrical specimens with diameter of $\phi 152 \mathrm{~mm}$ and height of $305 \mathrm{~mm}$ 
were fabricated in total. The cylinders were made of concrete with mean compressive strength of $105 \mathrm{MPa}$ (HSC) and $45 \mathrm{MPa}$ (NSC). The specimens were strengthened with two kinds of composites: the AFRP aramid and the CFRP carbon. The strengthening involved confining the specimens with 2-6 layers of a FRP sheet. The elements made of NSC were wrapped with 2 or 3 FRP layers. The HSC elements were wrapped with 4 or a maximum of 6 FRP layers.

The specimens made of the high-strength HSC concrete underwent failure by shearing along one plane without visible damage across the specimen. In case of specimens out of normal-strength NSC concrete, the cracks were more uniform and a greater part of the concrete was crushed before the rupture of the FRP jacket. The Authors concluded that normal stress curves for the specimens loaded cyclically can be obtained by connecting maxima of the $\sigma-\varepsilon$ schedules in subsequent cycles. The test results indicate that $\sigma-\varepsilon$ curves for the strengthened specimens subjected to cyclic axial load correspond with $\sigma-\varepsilon$ curves for the same concrete under monotonic load. In the authors' opinion, this observation is in accordance with the hypothesis formulated by Lam et al. (2006). The hypothesis says that a cyclic load induces strains which correspond to the $\sigma-\varepsilon$ curve for concrete within the range of the same monotonic load. HSC displays much better structural properties in comparison to NSC and offers an advantageous alternative to other building materials. On the other hand, application of HSC in case of cyclic loads can pose a serious threat because of load character and material brittleness.

The behaviour characteristic for a concrete element strengthened with an external CRFP jacket manifests by sudden failure without load-bearing capacity exhaustion symptoms. Wrapping a column with continuous CFRP jacket makes the observation of a confined concrete core impossible. It leads to loss of control over the heavily exerted element, gradually penetrated by internal microdamages leading to brittle destruction. More predictable and less destructive is the failure mechanism of elements strengthened with combined longitudinal and transverse CFRP reinforcements. In that case, a concrete core is stiffened with longitudinal strips held by confinement of a CFRP sheet (Trapko et al. 2012; Trapko, Musiał 2010, 2011). Failure of those elements is accompanied by crushing of the longitudinal CFRP strip. It is extremely important to recognise and monitor the technical state of key elements, which are usually structures subjected to cyclic loads. Destruction of a support usually causes disastrous consequences (failure of the entire structure). That is the reason why correct forecasting of the state of stress and the load-bearing capacity of elements strengthened with CFRP composites is so important.

This paper presents the results of a recent experimental study on the behavior of CFRP-confined concrete under cyclic compression. The leitmotif of the studies conducted is the influence of longitudinal and transverse CFRP strengthening on the state of effort of compressed elements.

\section{Experimental research}

The investigation involved 2 stages. 12 cylindrical specimens with diameter of $113 \mathrm{~mm}$ and height of $300 \mathrm{~mm}$ were tested at each stage. At each stage, 9 specimens were strengthened with CFRP materials and 3 specimens were tested as references. Specimens were strengthened with transverse CFRP sheets only at the $1^{\text {st }}$ stage. At the $2^{\text {nd }}$ stage longitudinal (CFRP strips) and transverse (CFRP sheet) strengthening were applied together. The undertaken experiments aimed to prove the effectiveness of longitudinal and transverse CFRP strengthening of compressed concrete elements subjected to cyclic loads.

\section{Preparation of test specimens}

Concrete mix, for designing grade $\mathrm{C} 25 / 30$ (PN-EN 206-1 2003), was made under laboratory conditions. A type CEM II 32,5R (PN-EN 197-1 2002) Portland cement was used. The fine aggregate used was $0-2 \mathrm{~mm}$ river sands. The coarse aggregate was $2-8$ and $8-16 \mathrm{~mm}$ river gravels. Mix proportions for the concrete mix used in this study are presented in Table 1 . Ingredients for the mix were measured out using a scale. The investigated elements and specimens for determining concrete properties were cast in steel moulds from a single batch of concrete. Concrete was compacted on a vibrating table. After two days the specimens were removed from the moulds and kept in a climatic chamber on a grate over the surface of water in temperature of $20 \pm 2{ }^{\circ} \mathrm{C}$.

Table 1. Concrete mix proportions

\begin{tabular}{lc}
\hline Portland cement CEM II 32,5R & $404 \mathrm{~kg} / \mathrm{m}^{3}$ \\
Sand 0-2 mm & $627 \mathrm{~kg} / \mathrm{m}^{3}$ \\
Gravel 2-8 mm & $537 \mathrm{~kg} / \mathrm{m}^{3}$ \\
Gravel $8-16 \mathrm{~mm}$ & $627 \mathrm{~kg} / \mathrm{m}^{3}$ \\
Water & $175 \mathrm{l} / \mathrm{m}^{3}$ \\
\hline
\end{tabular}

Strengthening was carried out with materials of the Sika CarboDur and the SikaWrap systems (Technical approval 2011). Strength parameters were taken from own investigations described in the paper of Trapko (2010):

- mean modulus of elasticity of the CFRP strips: $228 \mathrm{GPa}$;

- mean tensile strength of the CFRP strips: $3467 \mathrm{MPa}$;

- mean modulus of elasticity of the CFRP sheets: $238 \mathrm{GPa}$;

- mean tensile strength of the CFRP sheets: $2937 \mathrm{MPa}$.

\section{Properties of the concrete}

Specimens for determining properties of concrete were drawn during the preparation. The specimens were made and kept in a climatic chamber together with the investigated elements. The day before the beginning of experimental studies, the following parameters were determined:

- mean modulus of elasticity of the concrete: $29.8 \mathrm{GPa}$;

- mean cylinder compressive strength of the concrete: $31.6 \mathrm{MPa}$. 


\section{Experimental research methodology}

Before the test, the investigated elements were capped with steel plates to provide parallelism of pressure planes and axiality of the load. The schematic view of the elements is presented in Fig. 1. Gaps between the planes of the specimen and the steel cap were filled with quartz sands.

Stage I

Stage II
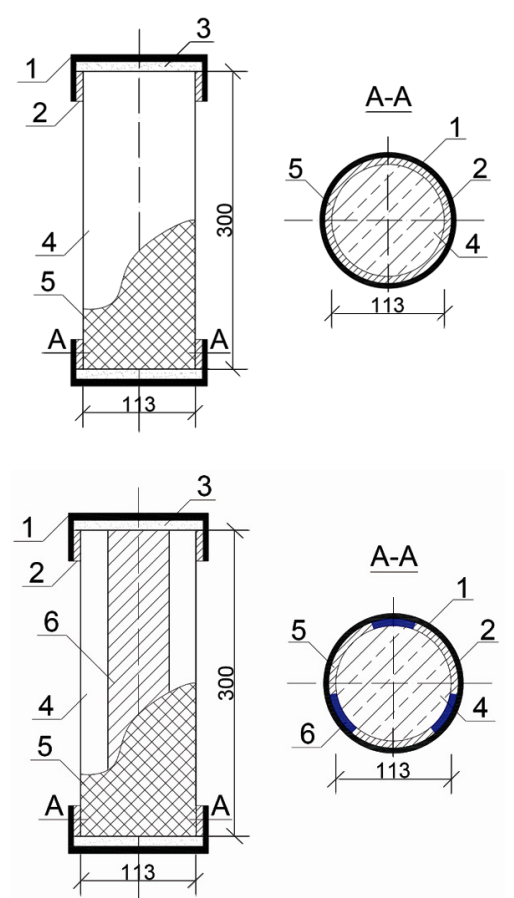

1 - steel cap; 2 - paraffin wax; 3 - quartz sands; 4 - concrete specimen; 5 - CFRP sheet; 6 - CFRP strip

Fig. 1. Fabricated specimens

Longitudinal and transverse strains were measured with strain gauges arranged across the external CFRP jacket. The gauges were attached in the middle of specimen height across the distance of $120^{\circ}$ around the cylinder perimeter. Each of the elements was provided with six strain gauges. Three gauges registered longitudinal strains and three transverse strains. Data was acquired each second.

Each specimen was designated as $\mathbf{T} i j_{-} k$, where $i$ stands for the number of the investigation stage, $j-$ the number of CFRP sheet layers applied (thickness per layer is $0.131 \mathrm{~mm}$ ) and $k$ - the order in particular subgroup.

One of the control specimen from each series Ti_0_a, Ti_1_a, Ti_2_a and T $i \_3 \_$a was subjected to monotonic compression until failure (Fig. 2). It allowed to determine the value of destructive force. On that basis the increase of force over a single load-unload cycle was then estimated. The increase of load over each cycle was $10 \%$ of the $\mathrm{N}_{\mathrm{u}}$ destructive force for the control specimen. The unloading cycle was finished at the load level of $10 \mathrm{kN}$ (without complete unloading). It prevented the specimen from any movement in the hydraulic press.

The specimens of each series, marked with symbols $\mathbf{T} i j_{-} \mathrm{b}$ and $\mathbf{T} i j_{-} \mathrm{c}$, were subjected to repeatedly alternating load. The load and unload cycles are schematically presented in Fig. 3.

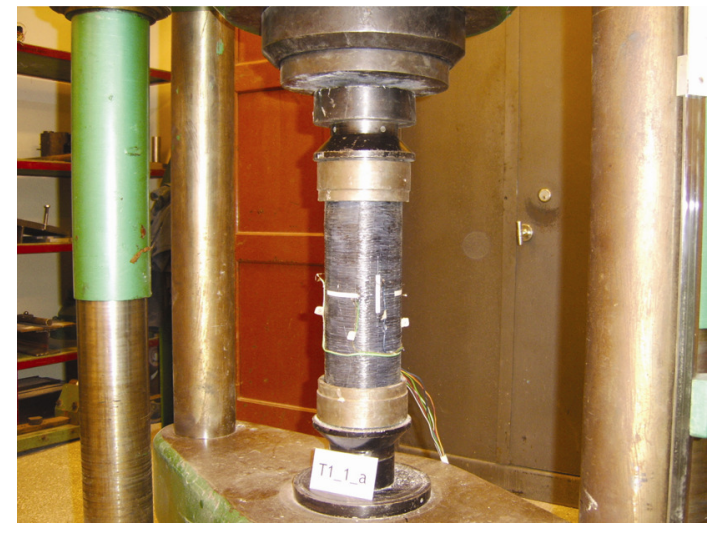

Fig. 2. Specimen T1_1_a in experimental setup

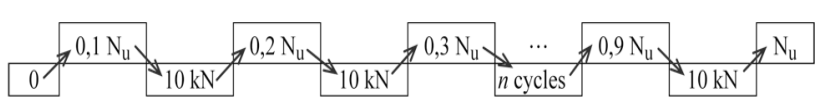

Fig. 3. Schematically presented investigative procedure

\section{Stage I}

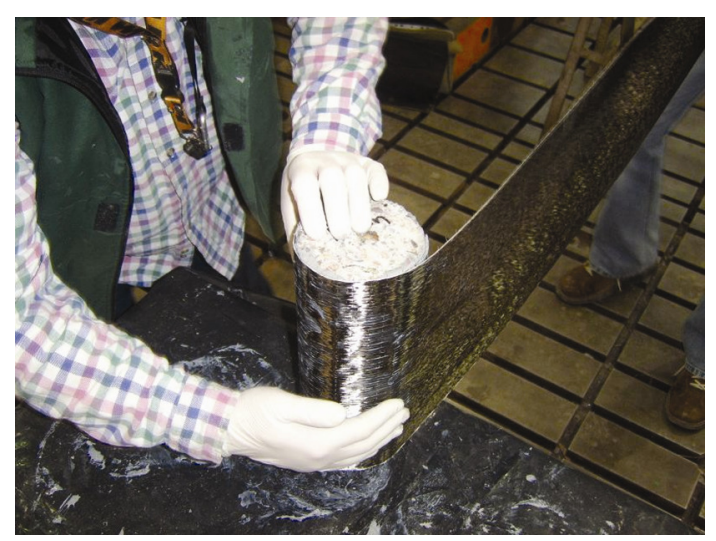

Fig. 4. Specimens preparation - stage I

At the $1^{\text {st }}$ stage the specimens strengthened (wrapped) with 1, 2 or 3 layers of transverse CFRP sheet were subjected to monotonic and cyclic compression (Table 2). The laminar strengthenings were made of one continuous sheet. Each specimen was applied with a $70 \mathrm{~mm}$ end overlap (Fig. 4), i.e. $20 \%$ of the specimen's circumference.

\section{Results of the $1^{\text {st }}$ stage investigations}

The aim of the destructive tests was to estimate the limit load capacity of the strengthened $\mathrm{N}_{\mathrm{u}}$ elements. It answered to a destructive force registered in the last loading cycle during compression (Table 3 ).

All of the strengthened elements, regardless of the way load was applied - monotonically or cyclically, were damaged in a similar fashion - by rupture of the external CFRP sheet. The concrete core failed and the level of break-up depended on the number of sheets confining the cross-section (Fig. 5). In case of the specimen $\mathbf{T} 1 \_3$ b, the load process was terminated upon destruction, in order to estimate the influence of cyclic load on the state of the concrete core. The specimen was cut through and the 
Table 2. Investigations program at stage I

\begin{tabular}{lcccccc}
\hline & T1_0_a & T1_0_b & T1_0_c & T1_1_a & T1_1_b & T1_1_c \\
\hline Number of specimens & 1 & 1 & 1 & 1 & 1 & 1 \\
\hline Transverse reinforcement & - & - & - & 1xCFRP sheet & 1xCFRP sheet & 1xCFRP sheet \\
\hline & T1_2_a & T1_2_b & T1_2_c & T1_3_a & T1_3_b & T1_3_c \\
\hline Number of specimens & 1 & 1 & 1 & 1 & 1 & 1 \\
\hline \multirow{2}{*}{ Transverse reinforcement } & $\begin{array}{c}\text { 2xCFRP } \\
\text { sheets }\end{array}$ & $\begin{array}{c}\text { 2xCFRP } \\
\text { sheets }\end{array}$ & $\begin{array}{c}\text { 2xCFRP } \\
\text { sheets }\end{array}$ & $\begin{array}{c}\text { 3xCFR } \\
\text { sheets }\end{array}$ & $\begin{array}{c}\text { 3xCFR } \\
\text { sheets }\end{array}$ & $\begin{array}{c}\text { 3xCFRP } \\
\text { sheets }\end{array}$ \\
\hline
\end{tabular}

Table 3. Tests results - stage I

\begin{tabular}{ccccc}
\hline No. & Specimen & Transverse CFRP layers & Type of loading & Load-bearing capacity [kN] \\
\hline 1 & T1_0_a & 0 & monotonic & 342.29 \\
2 & T1_0_b & 0 & cyclic & 399.26 \\
3 & T1_0_c & 0 & cyclic & 340.01 \\
\hline 4 & T1_1_a & 1 & monotonic & 516.21 \\
5 & T1_1_b & 1 & cyclic & 577.28 \\
6 & T1_1_c & 1 & cyclic & 534.20 \\
\hline 7 & T1_2_a & 2 & monotonic & 749.31 \\
8 & T1_2_b & 2 & cyclic & 864.07 \\
9 & T1_2_c & 2 & cyclic & 828.17 \\
\hline 10 & T1_3_a & 3 & monotonic & 964.64 \\
11 & T1_3_b & 3 & cyclic & - \\
12 & T1_3_c & 3 & cyclic & 1065.00 \\
\hline
\end{tabular}

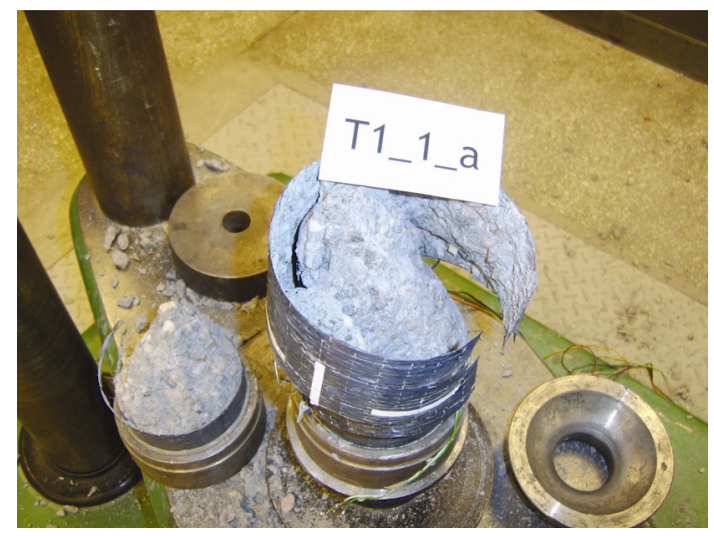

Fig. 5. Typical failure of CFRP confined concrete cylinders during a compression test - stage I

core was submitted for a visual assessment. Microdamages were found in the aggregate and cement matrix, what is marked in Fig. 6. It demonstrates the progressive process of concrete core destruction, which persisted despite internal composite jacket remaining intact. It should be considered as a potential threat because it leads to a loss of control over heavily exerted elements of a structure.

The longitudinal strains $\varepsilon_{\mathrm{vm}}$ and transverse strains $\varepsilon_{\mathrm{hm}}$ charts in function of stress for series $\mathbf{T} 1$ are presented in Figs 7, 8 and 11.

The results obtained for the elements loaded monotonically i.e. T1_1_a, T1_2_a and T1_3_a confirmed those already proven across literature sources. They proved that strains and load-bearing capacity of strengthened elements depend on transverse strengthening intensity (Fig. 7). With the increase of the number of CFRP sheet layers, limit strains and the load-bearing capacity increase as well. The results confirm the advantageous influence of transverse strengthening. In case of the specimens with

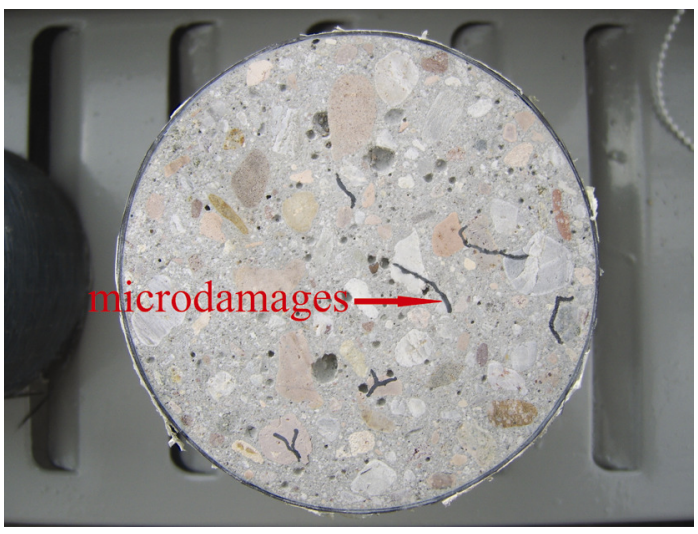

Fig. 6. View of specimen T1_3_b after cross-cut in the half of height

3 layers of sheet a three-fold increase of the load-bearing capacity in relation to un-strengthened specimens was found. The limit longitudinal strains increased significantly from $6 \%$ by adding one layer of sheet (T1_1_a) to $11 \%$ by adding three layers (T1_3_a).

As illustrated in Fig. 8, longitudinal $\varepsilon_{\mathrm{vm}}$ strain curves for the elements loaded monotonically and cyclically was very consistent for T1_1 series elements. In case of the transverse $\varepsilon_{\mathrm{hm}}$ strains in the $\mathbf{T} 1 \_1$ series elements loaded cyclically they were $25 \%$ lower than the strains in the elements loaded monotonically by the same effort levels, what should be considered a positive observation.

At an insignificant effort level, loading and unloading curves are practically linear. Over the subsequent cycles unloading curves are always nonlinear, whereas curves of recurrent load are linear but they do regain the level of strain before unloading (Fig. 9). Significant load degradation is noticeable. It means that the $\varepsilon_{(\mathrm{n}-1)}$ cycle strains (point R) are lower than the strains over the $\varepsilon_{(\mathrm{n})}$ 
cycle (point $U$ ) at the same stress level. This shift of the unloading/reloading curve indicates a cumulative effect of the loading history on the permanent strain. After exceeding the values of returning strains in cycle $\varepsilon_{(\mathrm{n})}$ (point $S$ ), the loading curve takes a nonlinear course (section S-W) until strains in the $\varepsilon_{(\mathrm{n})}$ cycle (point W) are reached, then the next unloading is started. The residual strains in cycle $\varepsilon_{\text {res(n) }}$ (point $\mathrm{T}$ ) are lower than the residual strains in cycle $\varepsilon_{\mathrm{res}(\mathrm{n}+1)}$ (point X).

The change of the secant Young modulus by unloading $\left(\mathrm{E}_{\text {sec_u }}\right)$ and reloading $\left(\mathrm{E}_{\text {sec__}_{-}}\right)$is presented in Fig. 10. The unloading secant stiffness $\left(\mathrm{E}_{\mathrm{sec} \_}\right)$is not equal to the reloading secant stiffness $\left(E_{\text {sec___}_{-}}\right)$. The $E_{\text {sec _u }_{u}}$ is always greater than the corresponding $\mathrm{E}_{\text {sec }_{-} \text {. }}$

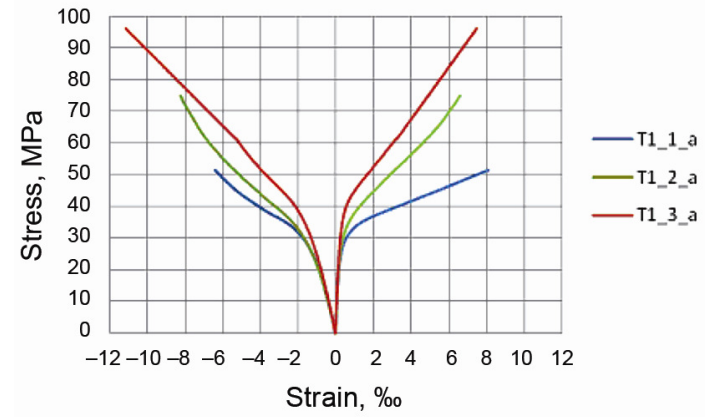

Fig. 7. Monotonic stress-strain curves for T1_1_a, T1_2_a and T1_3_a specimens

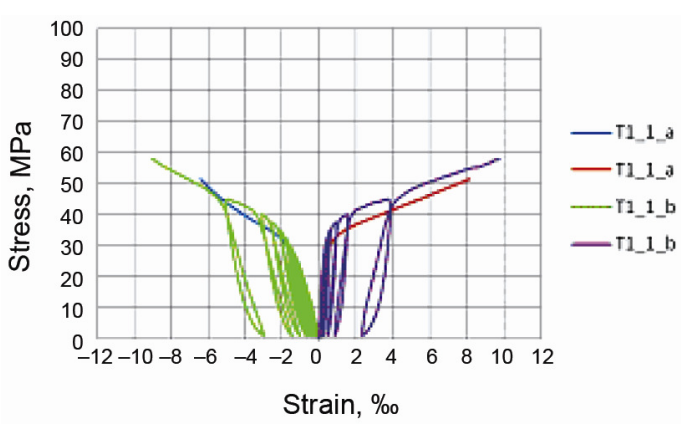

a) T1_1_a and T1_1_b

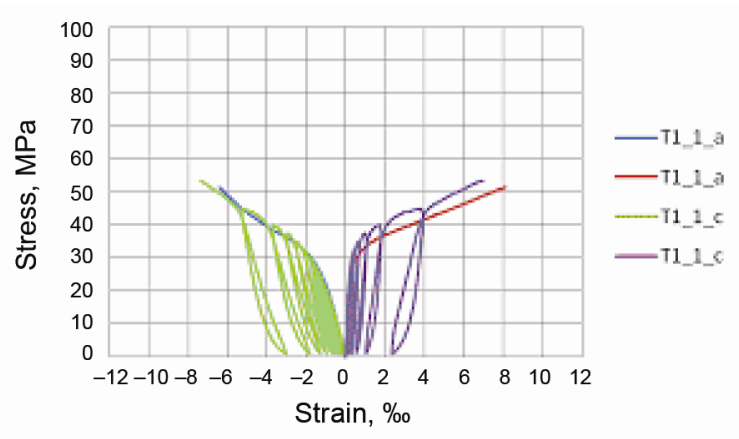

b) T1_1_a and T1_1_c

Fig. 8. Cyclic and monotonic stress-strain curves for $\mathbf{T} 1 \_1 \_a / b$ and T1_1_a/c specimens

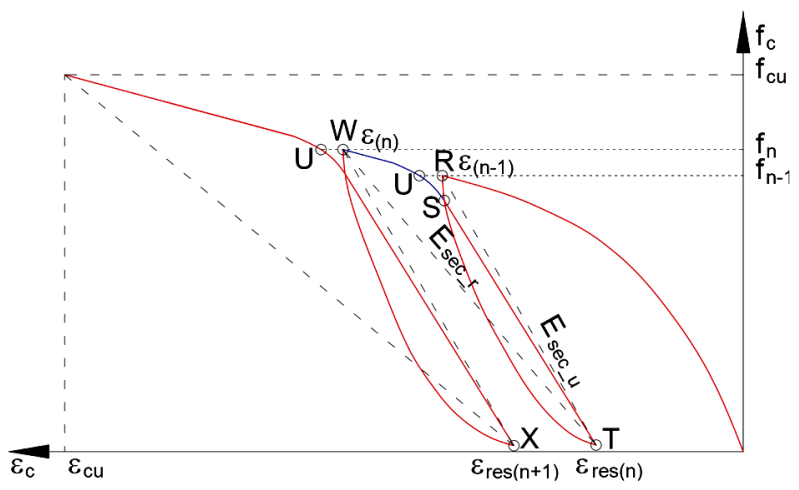

Fig. 9. $\sigma-\varepsilon$ relationship through cyclic loading

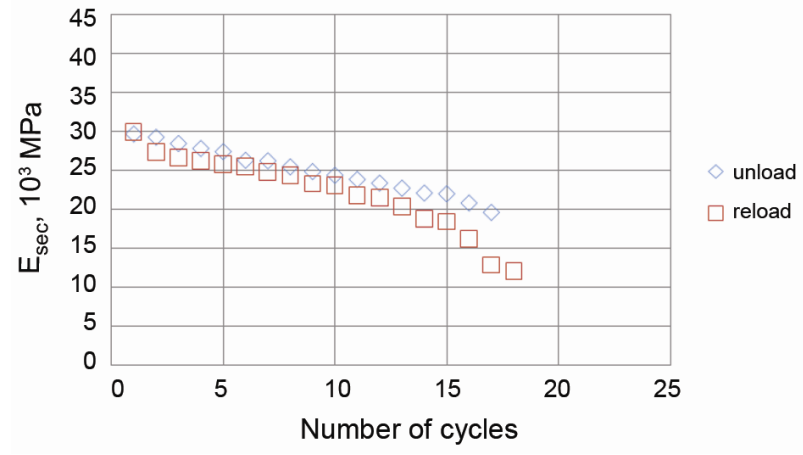

a) T1_1_c

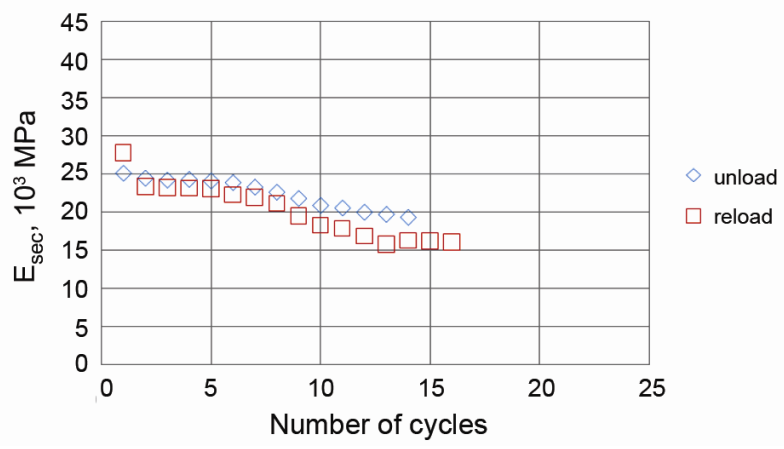

b) T1_2_c

Fig. 10. The change of secant cyclic Young modulus for the specimens T1_1_c and T1_2_c

In case of the T1 2 and $\mathbf{T} 1 \_3$ series elements subjected to repeatedly alternating load it was noticed that the fibres of the strengthening oriented perpendicularly to the loading direction, after repeated reloading and unloading underwent compression and stable deformation. It was observed that after consecutive unloading processes the residual strains increased, thus validating progressive deformation of the CFRP jacket. The paths of the strains $\sigma-\varepsilon$ over the last cycles are practically vertical, what means that the composite lost the ability for further interaction with deformable concrete core along the longitudinal direction (Fig. 11). 


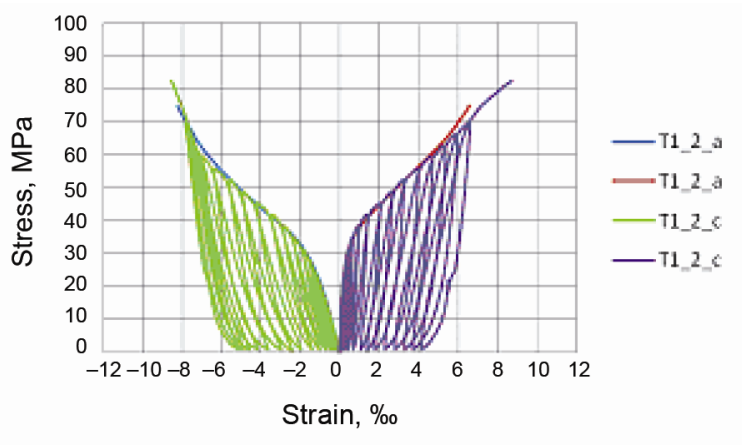

a) T1_2_a and T1_2_c

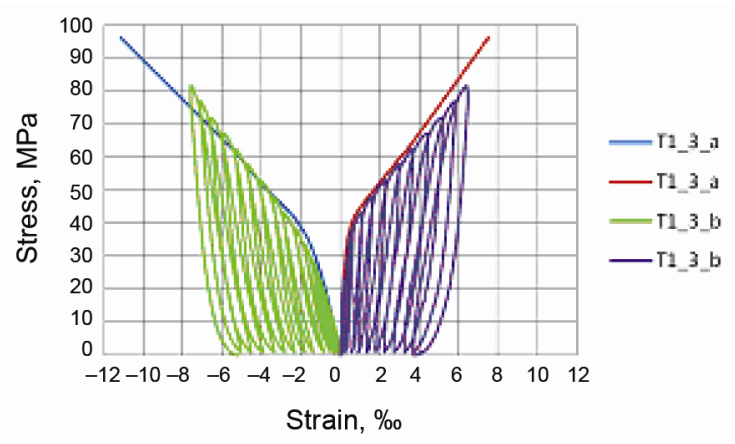

b) T1_3_a and T1_3_b

Fig. 11. Cyclic and monotonic stress-strain curves for T1_2_a/c and T1_3_a/b specimens

\section{Stage II}

At the $2^{\text {nd }}$ stage the specimens strengthened with longitudinal strips and wrapped with 1, 2 or 3 layers of a CFRP sheet were subjected to monotonic and cyclic compression (Table 4). On the concrete surface, across the distance of $120^{\circ}$, three longitudinal segments of CFRP strips of $60 \mathrm{~mm}$ breadth and thickness of $1.2 \mathrm{~mm}$ were attached. The stripes were incised in the longitudinal direction before fitting the shape to the side curvature of cylinder (Fig. 12).

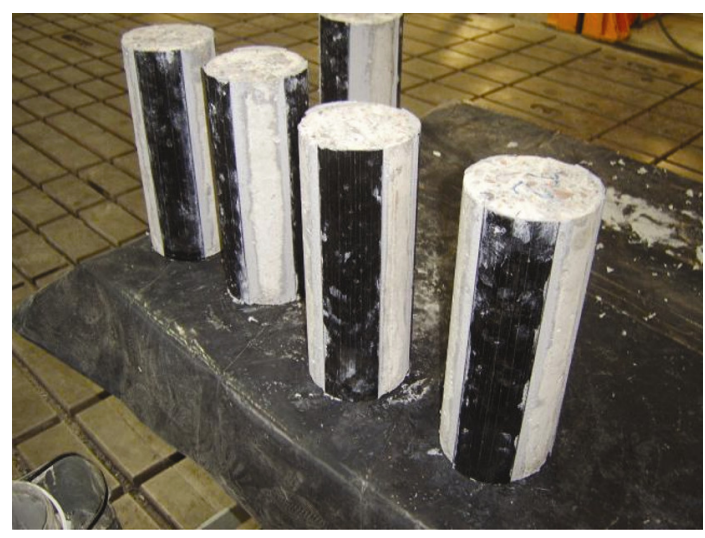

Fig. 12. Specimens preparation - stage II

\section{Results of $2^{\text {nd }}$ stage investigations}

As aforementioned at the beginning, application of longitudinal CFRP strengthening limits destruction of the element. The concrete core, despite partial crushing, remains intact held by longitudinal strips and the transverse sheet (Fig. 13). The results of the destructive test were gathered in Table 5.

Subsequent diagrams (Fig. 14) present $\sigma-\varepsilon$ relationships for elements strengthened with longitudinal segments of CFRP strips (T2_1_a, T2_2_a and T2_3_a) subjected to monotonic load. The comparison of results for the strengthened elements of $\mathbf{T} 1$ and $\mathbf{T} 2$ series loaded monotonically, shows a significant influence of longitudinal CFRP strengthening on the mean compressive strains. The differences between longitudinal limit strains $\varepsilon_{\mathrm{vm}, \text { lim }}$ for the elements of both series were compared in Table 6. In case of elements of $\mathbf{T} 2$ series loaded monotonically, the intensity of transverse strengthening does not influence significantly the longitudinal compressive strains. Presence of longitudinal strengthening is the critical factor in this case (Trapko et al. 2012; Trapko, Musiał 2011).

It should be noted that the transverse strains curves for the T2 1 1 b and $\mathbf{T} 2 \_1$ elements are below the curve for the T2_1_a reference element loaded monotonically.

At the same effort levels the cyclical transverse strains are greater than the monotonic, what should be recognized as disadvantageous (Fig. 15). During the destruction phase, after external CFRP jacket rapture, the transverse delamination of the strips was noticed. It could happen during load cycles and consequently cause such strains (Fig. 16).

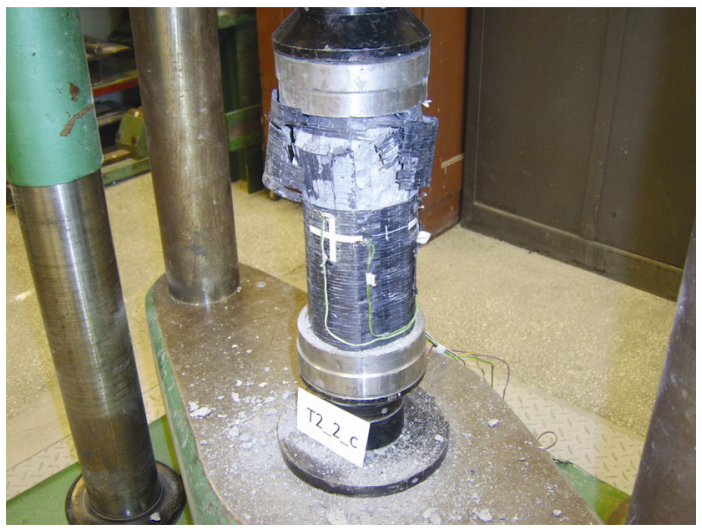

Fig. 13. Typical failure of CFRP confined concrete cylinders in a compression test - stage II

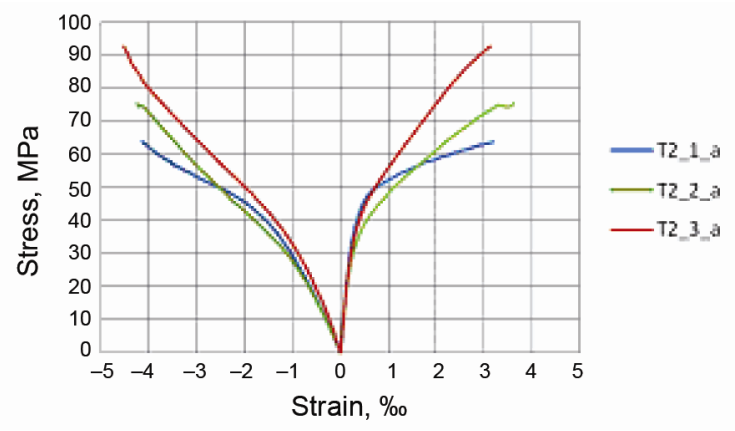

Fig. 14. Monotonic stress-strain curves for $\mathbf{T} 2 \_1 \_a, T 2 \_2 \_$a and T2_3_a specimens 
Table 4. Investigations program at stage II

\begin{tabular}{|c|c|c|c|c|c|c|}
\hline & T2_0_a & $\mathbf{T} 2 \_0 \_b$ & T2_0_c & T2_1_a & T2_1_b & T2_1_c \\
\hline $\begin{array}{l}\text { Number of speci- } \\
\text { mens }\end{array}$ & 1 & 1 & 1 & 1 & 1 & 1 \\
\hline $\begin{array}{l}\text { Longitudinal } \\
\text { reinforcement }\end{array}$ & - & - & - & $\begin{array}{c}3 \times C F R P \text { strips } \\
60 \times 1.2 \mathrm{~mm}\end{array}$ & $\begin{array}{l}3 \times C F R P \text { strips } \\
60 \times 1.2 \mathrm{~mm}\end{array}$ & $\begin{array}{c}3 \times C F R P \text { strips } \\
60 \times 1.2 \mathrm{~mm}\end{array}$ \\
\hline \multirow[t]{2}{*}{$\begin{array}{l}\text { Transverse rein- } \\
\text { forcement }\end{array}$} & - & - & - & 1xCFRP sheet & 1xCFRP sheet & 1xCFRP sheet \\
\hline & T2_2_a & T2_2_b & T2_2_c & T2_3_a & T2_3_b & T2_3_c \\
\hline $\begin{array}{l}\text { Number of speci- } \\
\text { mens }\end{array}$ & 1 & 1 & 1 & 1 & 1 & 1 \\
\hline $\begin{array}{l}\text { Longitudinal } \\
\text { reinforcement }\end{array}$ & $\begin{array}{l}\text { 3xCFRP strips } \\
60 \times 1.2 \mathrm{~mm}\end{array}$ & $\begin{array}{c}\text { 3xCFRP strips } \\
60 \times 1.2 \mathrm{~mm}\end{array}$ & $\begin{array}{c}\text { 3xCFRP strips } \\
60 \times 1.2 \mathrm{~mm}\end{array}$ & $\begin{array}{c}3 \times C F R P \text { strips } \\
60 \times 1.2 \mathrm{~mm}\end{array}$ & $\begin{array}{c}\text { 3xCFRP strips } \\
60 \times 1.2 \mathrm{~mm}\end{array}$ & $\begin{array}{c}\text { 3xCFRP strips } \\
60 \times 1.2 \mathrm{~mm}\end{array}$ \\
\hline $\begin{array}{l}\text { Transverse rein- } \\
\text { forcement }\end{array}$ & $2 \mathrm{xCFRP}$ sheets & 2xCFRP sheets & $\begin{array}{l}\text { 2xCFRP } \\
\text { sheets }\end{array}$ & $\begin{array}{l}\text { 3xCFRP } \\
\text { sheets }\end{array}$ & $3 x C F R P$ sheets & $\begin{array}{l}\text { 3xCFRP } \\
\text { sheets }\end{array}$ \\
\hline
\end{tabular}

Table 5. Tests results - stage II

\begin{tabular}{c|c|c|c|c}
\hline No. & Specimen & Transverse CFRP layers & Type of loading & Load-bearing capacity [kN] \\
\hline 1 & T2_0_a & 0 & monotonic & 330.80 \\
\hline 2 & T2_0_b & 0 & cyclic & 399.26 \\
\hline 3 & T2_0_c & 0 & cyclic & 340.01 \\
\hline 4 & T2_1_a & 1 & monotonic & 638.16 \\
\hline 5 & T2_1_b & 1 & cyclic & 672.00 \\
\hline 6 & T2_1_c & 1 & cyclic & 605.48 \\
\hline 7 & T2_2_a & 2 & monotonic & 754.70 \\
\hline 8 & T2_2_b & 2 & cyclic & 749.70 \\
\hline 9 & T2_2_c & 2 & cyclic & 774.86 \\
\hline 10 & T2_3_a & 3 & cyclic & 929.92 \\
\hline 11 & T2_3_b & 3 & cyclic & 847.86 \\
\hline 12 & T2_3_c & 3 & & 817.92 \\
\hline
\end{tabular}

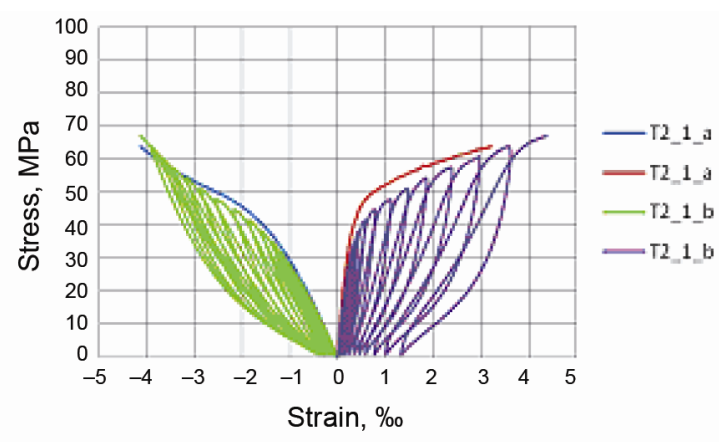

a) T2_1_a and T2_1_b

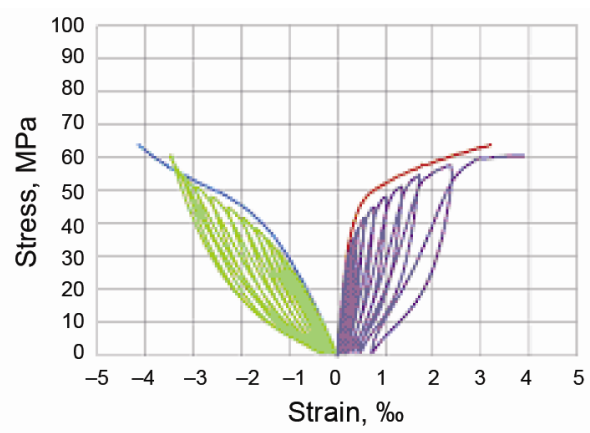

b) T2_1_a and T2_1_c

Fig. 15. Cyclic and monotonic stress-strain curves for T2_1_a/b and T2_1_a/c specimens
Table 6. The comparison of the longitudinal limit strains of the elements of $\mathbf{T} 1$ a and $\mathbf{T} 2$ _a series

\begin{tabular}{ccc}
\hline & $\varepsilon_{\mathrm{vm}, \mathrm{lim}}[\% \mathrm{o}]$ & $\Delta \varepsilon_{\mathrm{vm}}[\% \mathrm{o}]$ \\
\hline T1_1_a & -6.406 & -2.264 \\
T2_1_a & -4.142 & -4.015 \\
\hline T1_2_a & -8.213 & -6.605 \\
T2_2_a & -4.198 & -11.130 \\
\hline T1_3_a & -4.525 & \\
T2_3_a &
\end{tabular}

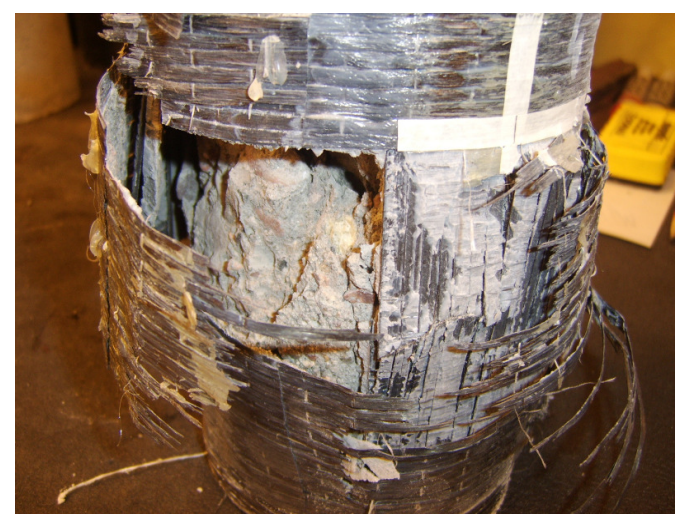

Fig. 16. Typical failure of CFRP confined concrete cylinders during a compression test - stage II 


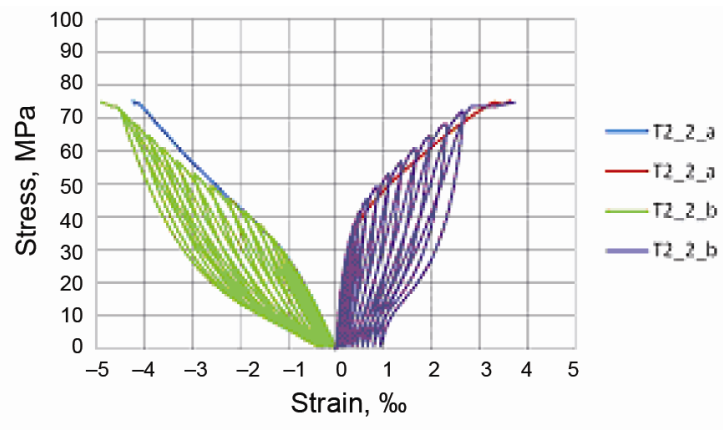

a) T2_2_a and T2_2_b

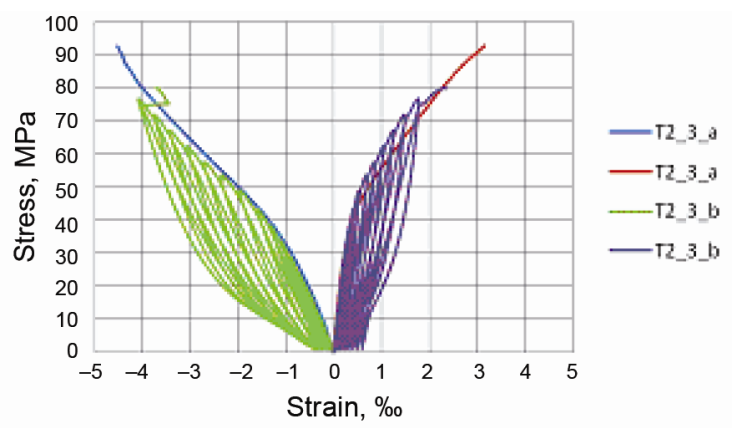

b) T2_3_a and T2_3_b

Fig. 17. Cyclic and monotonic stress-strain curves for the T2_2_a/b and T2_3_a/b specimens

In case of the elements of T2_2 and T2_3 series (Fig. 17), strengthened with longitudinal CFRP strips and two or three layers of CFRP sheet respectively, subjected to cyclic load, the curves of longitudinal strains $\varepsilon_{\mathrm{vm}}$ for the elements loaded monotonically and cyclically were very consistent. In this case the transverse strains $\varepsilon_{\mathrm{hm}}$ in elements subjected to cyclic load are lower than the strains in elements loaded monotonically, at the same effort levels. In comparison to the elements of T2_1 series, the transverse sheet managed to prevent the transverse delamination of the strips.

In case of cyclic loads, it is interesting whether global residual strains stabilize after certain number of cycles, what would cause the Young modulus to remain constant at cyclic $\mathrm{E}_{\text {cyclic }}$ load. The value of $\mathrm{E}_{\text {cyclic }}$ can be calculated provided inclination angles between tangent chords (increasing $\mathrm{E}_{\mathrm{sec} \_\mathrm{r}}$ and decreasing $\mathrm{E}_{\mathrm{sec \_} \_}$) approach the common limit (Fig. 9). Such analysis was carried out based on results for the elements tested i.e. T2 $1 \_b$, T2 2_c and T2 3 b (Fig. 18). It is clear that stabilization of the Young modulus occurred already over the initial cycles. They approached the limit values (T2_1_b $\mathrm{E}_{\mathrm{cy}-}$ clic $\approx 17000 \mathrm{MPa}, \mathbf{T} 2 \_2 \_\mathrm{c} \mathrm{E}_{\mathrm{cyclic}} \approx 18500 \mathrm{MPa}, \mathrm{T} 23$ _b $\mathrm{E}_{\mathrm{cy}-}$ ${ }_{\text {clic }} \approx 20000 \mathrm{MPa}$ ). In case of the elements strengthened with the CFRP sheet, the opposite proved to be the case. Stabilization of the residual strains and the cyclic Young modulus $\mathrm{E}_{\text {cyclic }}$ were not observed, as presented in Fig. 9.

Investigations of strains in plain or steel-confined concrete elements suggest that the $\varepsilon_{\text {res }}$ residual strains in concrete are a linear function of the unloading strain $\varepsilon_{\mathrm{un}}$ (Sakai, Kawashima 2006; Sinha et al. 1964). According to Fig. 19, elements strengthened with CFRP sheet (T1_1_c and T1_2_c) should take a nonlinear function, which depends on the number of sheet layers to a minor extent. Because of the above-mentioned, the linear function proposed by Lam et al. (2006) is unacceptable. With each load - unload cycle the same relative increase of the residual strains does not occur i.e. $\Delta \varepsilon_{\text {res }}=\varepsilon_{\text {res }(\mathrm{n}+1)}-\varepsilon_{\text {res(n) }} \neq$ const. and it depends on the effort level. Whereas for the elements of $\mathbf{T} 2$ series the factor critical for forecasting the state of strain was the level of strains of $\varepsilon_{\text {un }}=2.50 \%$. The Authors suppose that it equals the value of critical strains, given the delamination in the contact of strip and concrete could occur. Hence decompression (expansion) and decrease of the residual strains measured across the composite external surface (Fig. 19) were observed.

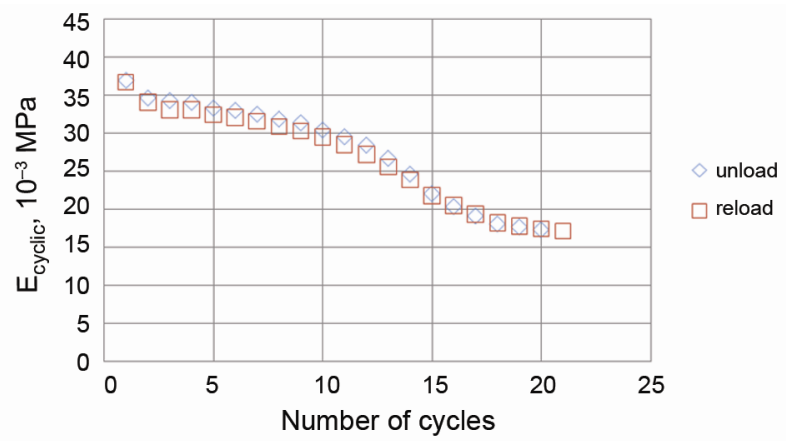

a) T2_1_b

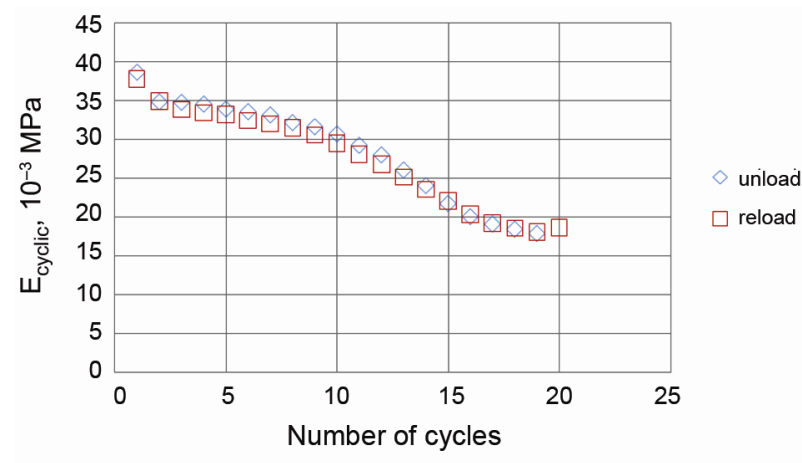

b) T2_2_c

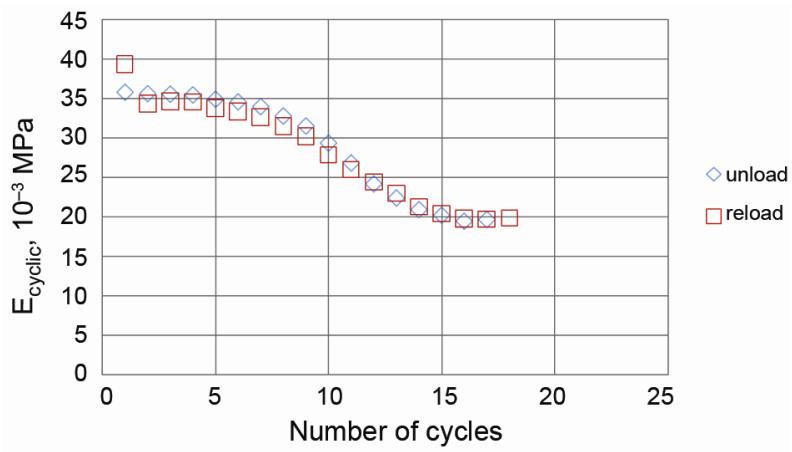

c) T2_3_b

Fig. 18. Change of the secant cyclic Young modulus of the specimens T2_1_b, T2_2_c and T2_3_b 


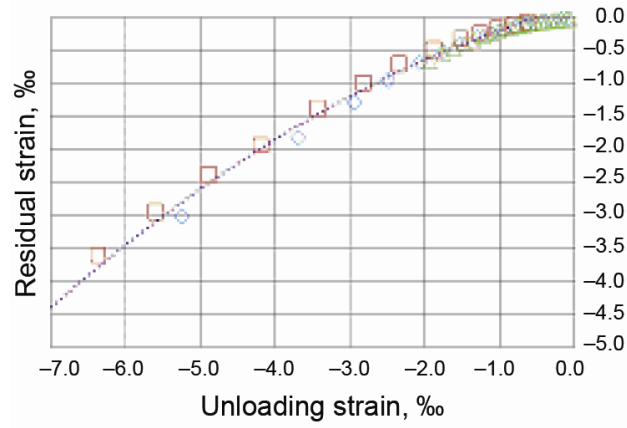

a) series $\mathbf{T} 1$

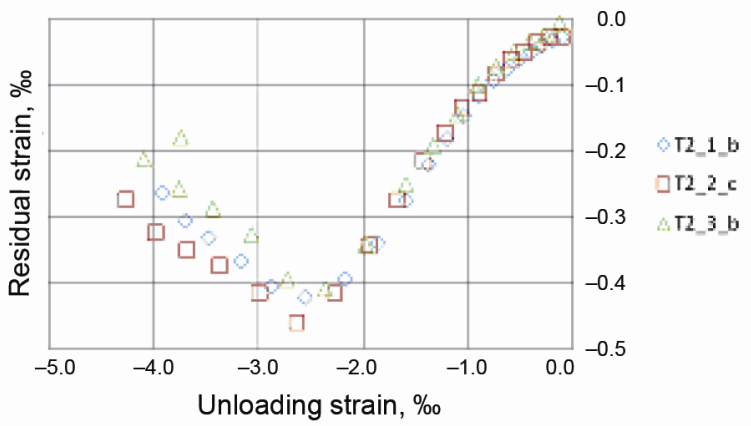

b) series $\mathbf{T} 2$

Fig. 19. Residual strain and envelope unloading strain

\section{Conclusions}

Based on completed experimental studies and results of analyses, the authors have drawn the following conclusions:

1. The effectiveness of CFRP strengthening for concrete elements subjected to cyclic compression depends on the state of effort of concrete and predominantly the interaction of both materials.

2. Strengthening heavily exerted cyclically compressed elements with two or more layers of transverse composite sheet should be perceived disadvantageous because of forecasting difficulties of strains and microcracks occurring in the concrete core.

3. Failure mechanism of the elements strengthened with two or more layers of transverse composite sheet has sudden and unsignalized course.

4. In elements subjected to cyclic compression, application of a single CFRP strengthening sheet is recommended, but only where repair is required, as it does not improve significantly t the loadbearing capacity.

5. The presence of longitudinal composite CFRP strengthening improves stiffness, what influences advantageously the state of strain and load-bearing capacity of elements subjected to cyclic loads.

6. For elements with both types of strengthening longitudinal and transverse, the cyclic Young modulus approaches a constant value depending on effort of the element.
7. In elements with both types of strengthening, the intensity of transverse strengthening does not influence significantly longitudinal compressive strains, whereas it does influence the state of transverse strain.

8. In case of elements subjected to cyclic compression an application of composite strengthening including longitudinal stripes with minimum two layers of sheet is recommended.

\section{References}

Campione, G.; Miraglia, N. 2003. Strength and strain capacities of concrete compression members reinforced with FRP, Cement and Concrete Composites 25(1): 31-41. http://dx.doi.org/10.1016/S0958-9465(01)00048-8

Demers, M.; Neale, K. W. 1994. Strengthening of existing concrete columns with unidirectional composite sheets, in Proc. of the 4th International Conference on Short and Medium Span Bridges, 8-11 August, 1994, Montreal, Canada, 895-905.

Gorzelańczyk, T. 2011. The effect of moisture content on the failure of self-compacting concrete under compression, as assessed by means of acoustic methods, Archives of Civil and Mechanical Engineering 11(1): 45-60.

Hoła, J. 2000. Naprężenia inicjujace $i$ krytyczne a destrukcja naprężeniowa $w$ betonie ściskanym [Relation of initiating and critical stress to stress failure], Scientific Papers of the Institute of Building Engineering of the Wrocław University of Technology, No. 76, Monographs No. 33, Wrocław University of Technology Publishing House, Wroclaw. 38 p.

Hoła, J. 2002. Experimentally determined effects of technological and service factors on stress-induced destruction of concrete under compression, Engineering Transactions 50(4): 251-265.

Ignatowski, P.; Kamińska, M. E. 2004. O ograniczeniu odkształceń betonu ściskanego kompozytami CFRP [On behavior of compressed concrete confined with CFRP composites], Inżynieria $i$ Budownictwo [Engineering and Construction], (4): 204-208.

Lagoda, M. 2005. Wzmacnianie mostów przez doklejanie elementów [Externally bonded reinforcement in bridge strengthening]. Cracow University of Technology, Cracow, Poland. 247 p.

Lam, L.; Teng, J. G.; Cheung, C. H.; Xiao, Y. 2006. FRPconfined concrete under axial cyclic compression, Cement and Concrete Composites 28(10): 949-958. http://dx.doi.org/10.1016/j.cemconcomp.2006.07.007

Ozbakkaloglu, T.; Lim, J. C.; Griffith, M. C. 2008. FRPconfined high-strength concrete under axial cyclic compression, in Proc. of the 4th International Conference on FRP Composites in Civil Engineering (CICE 2008), 2224 July, 2008, Zurich, Switzerland, on CD, Paper No. 6.A.2.

PN-EN 197-1:2002. Cement. Część 1: Skład, wymagania $i$ kryteria zgodności dotyczqce cementów powszechnego $u z ̇ y t k u$ [Cement - Part 1: Composition, specifications and conformity criteria for common cements]. Warsaw, 2002. $28 \mathrm{p}$.

PN-EN 206-1:2003. Beton. Część 1: Właściwości, produkcja, uktadanie i kryteria zgodności [Concrete - Part 1: Specification, performance, production and conformity]. Warsaw, 2003. 80 p. 
Rochette, P.; Labossière, P. 2000. Axial testing of rectangular column models confined with composites, Journal of Composites for Construction ASCE 4(3): 129-136. http://dx.doi.org/10.1061/(ASCE)1090-0268(2000)4: $3(129)$

Sakai, J.; Kawashima, K. 2006. Unloading and reloading stress - strain model for confined concrete, Journal of Structural Engineering ASCE 132(1): 112-122. http://dx.doi.org/10.1061/(ASCE)0733-9445(2006)132: $1(112)$

Shao, Y.; Zhu, Z.; Mirmiran, A. 2006. Cyclic modeling of FRPconfined concrete with improved ductility, Cement and Concrete Composites 28(10): 959-968. http://dx.doi.org/10.1016/j.cemconcomp.2006.07.009

Sinha, B. P.; Gerstle, K. H.; Tulin, L. G. 1964. Stress-strain relations for concrete under cyclic loading, ACI Journal 61(2): 195-211.

Technical approval Building Research Institute. No AT-155604/2011. Warsaw, 2011. 16 p.

Trapko, T. 2010. Identyfikacja parametrów wytrzymałościowych kompozytów węglowych CFRP [The identification of strength parameters of CFRP composites], Materiaty Budowlane [Construction Materials] (7): 29-31.
Trapko, T.; Kamiński, M.; Musiał, M. 2012. Investigations on rheological strains of compressed concrete elements strengthened with external composite reinforcement CFRP, Composite Part B: Engineering 43(3): 1417-1424. http://dx.doi.org/10.1016/j.compositesb.2011.09.009

Trapko, T.; Musiał, M. 2010 Strains of eccentrically compressed RC columns strengthened with CFRP sheets and strips, Journal of Materials Science and Engineering 4(7): 62-68.

Trapko, T.; Musial, M. 2011. The effectiveness of CFRP materials strengthening of eccentrically compressed reinforced concrete columns, Archives of Civil and Mechanical Engineering 11(1): 249-262.

Varma, R. K.; Barros, J. A. O.; Sena-Cruz, J. 2009. Numerical model for CFRP confined concrete elements subject to monotonic and cyclic loadings, Composites Part B: Engineering 40(8): 766-775. http://dx.doi.org/10.1016/j.compositesb.2009.05.005

Wojciech TRAPKO. MSc. Eng., graduated from the Faculty of Civil Engineering, Wroclaw University of Technology. Master's degree specializing in construction engineering. His interests: strengthening structures, numerical modelling MES.

Tomasz TRAPKO. Dr Eng., Assistant professor in the Concrete Construction Department Institute of Building Engineering, Wroclaw University of Technology. His research includes strengthening of RC concrete structures with a special emphasis on concrete columns using FRP composites. Member of the International Institute for FRP in Construction (IIFC) and the Polish Group IIFC. 